\title{
Research on the Application of Sports Bracelet in College Physical Education
}

\author{
Jianzhen Huang and Guoliang Wang \\ NanChang Institute of Science and Technology, Nanchang, 330108
}

Keywords: College physical education; Smart bracelet; Application; Feasibility

\begin{abstract}
Smart bracelet is a new wearable smart device that can record daily exercise, sleep, diet and other data and analyze these data to guide a healthy life. The feasibility of using smart bracelet in college physical education is discussed through logic analysis and literature method. The possibility of combining smart bracelet with college physical education is put forward, and the promotion prospect of smart bracelet in college physical education is put forward. The smart bracelet which is an emerging equipment can be better used in college sports, to guide students to have a healthier life and to enhance the health awareness of college students.
\end{abstract}

\section{Introduction}

Smart bracelet is a high-tech, wearable, smart device that has not been around for a while. Data show that in 2017, the world sold nearly 70 million smart wearable devices. With its powerful data collection and data analysis capabilities, smart bracelet has a vast market scenario and is known by more and more people. It shows that the smart bracelet is quietly appear in the life of college students. As an important part of our country's sports undertaking, college physical education is related to the enhancement of people's constitution, improvement of health level and improvement of quality of life. It is one of the most important symbols of civilization, health and science in modern colleges and universities. Smart bracelet is a new type of wearable smart device which plays an important role in the lives of current college students. Physical education in colleges and universities is an important part of the development of sports in our country and has a close relationship with people's sports and health. The application of smart bracelet in college sports center is of great significance.

\section{Smart Bracelet Application Status}

The internal part of smart bracelet is made from medical rubber material, which is natural and non-toxic. Smart bracelet design is more upscale fashion. Smart bracelet promotes healthy receipt in use, which is in line with the atmosphere of college and the current trend. The application of the smart bracelet in the university sports center has a higher demand for improving the health of all the members in the university. In a comprehensive economic development, college students pay more and more attention to their own health. College students are not optimistic about their overall condition of their health. Some teenagers' physique declines year by year. Osteoporosis symptoms are common in the elderly. The application of the smart bracelet can monitor the health of college students and can play a positive role in the further development of college sports, which can also play a positive role. The diversity of smart bracelets is the main reason for the popularity in college students. The diversity of smart bracelet features are as follows:

Functions of Fitness and Entertainment. The application of smart bracelet is more and more widespread, mainly because the functions of are more, including basic functions such as fitness and entertainment. Smart bracelet data analysis capability is relatively strong, for college students with different sports habits, it can develop individual characteristics of exercise intensity and plan. The pedometer function is the basic function. Combined with the body mass index, it can analyze walking step spacing and energy consumption, and then combined with personal daily walking habits, it develops walking program and the goal of walking every day. 
Function of Activity Records. The activity record function of smart bracelet is also very important. It can accurately record running, swimming, climbing and other sports activities in the hardware sensor .

Function of Social Networking Analysis. The application of the smart bracelet in the society has given full play to the social network sharing function. In the current era of Internet development, emerging social software appears to facilitate the social communication of college students.

\section{Feasibility Analysis on the Application of Smart Bracelet in College Physical Education}

Diversified physical education in colleges and universities provide power for physical education in colleges and universities. The development of anything needs an endless stream of motivation. College physical education is no exception. In today's society, colleges and universities are capable of cultivating a batch of new sports talents. Therefore, the purpose of physical education in colleges and universities should not only improve the physical quality of college students, but also cultivate talents with multi-aspects of sports abilities. Physical education in colleges and universities is a basic discipline in college teaching, which mainly includes theoretical teaching and practical classroom exercise. It is a discipline where all college students need to complete their credits. Physical education in colleges and universities cultivates students' awareness of sports self-awareness, sports attitude, sports values and so on. More importantly, physical teaching in colleges and universities should focus on giving full play to its various education needs to cater to the needs of the times. Colleges and universities should set up comprehensive physical education teaching and students should choose what they want to learn based on their own interests. Science and technology should be used and allow students to study sports according to their own interests, which essentially enhances students' enthusiasm for sports, provides impetus for the development of physical education in colleges and universities and helps to promote the development of physical education in colleges and universities.

Exercise Promotion Function of Smart Bracelet. Diverse sports is also to promote college students to exercise, which happens to coincide with the functions of fitness and entertainment of the smart bracelet. Based on powerful data analysis capabilities, according to different exercise habits, smart bracelet will develop exercise-specific intensity and plan for college students, such as the step-by-step function. First of all, according to personal body index, it will analyze walking step spacing and consumption energy, and according to the individual's usual habit of walking, develop the walking program with individual characteristics and develop a daily goal of walking.

To connect the smart bracelet to mobile application software will bring a different entertainment experience. In the mobile terminal, based on smart bracelet feedback data, the smart bracelet will communicate with the user. With the person's language, the smart bracelet will say "Come on, today's goal is almost done.""Get up, do not be sedentary.""It's fantastic. We are overfull filling the goal today." These other words will give some knowledge of sports science so that the user can take the initiative of "sports", rather than being dragged by "sports", which will make the user feel the benefits and fun of sports.

24-hour and 7-day Monitoring Function of Smart Bracelet. Colleges and universities require students to exercise according to the target, then the smart bracelet will be useful. Smart bracelet monitoring function is all-weather, no matter what form of exercises, no matter what the time is and where the user is, the smart bracelet can monitor the user, from exercise, sleeping and diet. The realization of these monitoring functions are all based on powerful smart sensors on the smart bracelet.

\section{The Promotion Prospects of Smart Bracelet in College Sports}

Smart Bracelet Creates the Specific Health Consciousness. Smart bracelet does not only perceive, record and analyze vital signs and sports data with the support of software, but also cultivates the health consciousness of college students and greatly improves their quality of life. Supported by the strong "Cloud of sports" data, students are unconsciously aware of and understand 
healthy lifestyles through the use of smart bracelets, and gradually develop their awareness of healthy living. With the passage of time, the health consciousness cultivated by the smart bracelet become everyday habits and normal, making the health awareness of college students be more specific. With the specific health awareness, college students will take the initiative in college physical exercise, which is the indirect transmission of college sports philosophy, and will also enhance the awareness of lifelong physical education.

Anytime and Anywhere Exercise Mechanism. Smart bracelet makes sports, sleep, diet be more scientific. Healthy lifestyles cannot do without the reasonable combination of exercise, sleep and diet. Smart bracelet scientifically records and analyzes the data relying on a powerful data processing system. The cross-analysis of these data can be used to analyze the user's physical condition well, and combined with the data, give personalized recommendations for several key physiological activities, such as exercise, sleep and diet, allowing users to always maintain a healthy state of life. The role of smart bracelet is like the user's "personal doctor" and "personal trainer", which can make a more personalized customization for users, making many people be willing to participate in sports.

\section{Conclusion}

From the perspective of the characteristics of the smart bracelet, it successfully implements a set of scientific feedback system that collects and analyzes the basic data of the user's body and guides the user's movement, which can be applied to college sports. Its flexibility and powerful cloud data processing capabilities make it a platform for college students to participate in college sports and can be a platform for sports enthusiasts. More scientific means are used to cultivate college students' interest in physical exercise so that college students can develop a sense of lifelong physical education. The concept of healthy exercise, healthy living will be deeply rooted in the hearts of people. Smart bracelet must become an effective way to promote the development of college sports. However, no matter how powerful the function of the smart bracelet is, it plays a secondary role in college sports. The scope of college sports is very wide and requires a lot of joint efforts. We need to speed up the integration of college sports resources, so that the smart bracelet can better serve college sports.

\section{References}

[1] Budig G A, Costas B. Grasping the Ring: Nine Unique Winners in Life and Sports[J].

[2] Galasso A G J. Betting against the House (and Senate): The Case for Legal, State-Sponsored Sports Wagering in a Post-PASPA World[J]. 2010.

[3] Calvert C, Richards R D. Fans and the First Amendment: Cheering and Jeering in College Sports[J]. Va.sports \& Ent.1.j.

[4] Harvey-Kelly K F, Obakponovwe O, Ahmad M, et al. Quality of life and sports return following pelvic ring injuries[J]. Injury Extra, 2011, 42(9):125-125.

[5] Cabot, Anthony. The Absence of a Comprehensive Federal Policy toward Internet and Sports Wagering and a Proposal for Change[J]. Jeffrey S Moorad Sports Law Journal, 2010.

[6] Cabot A. Absence of a Comprehensive Federal Policy toward Internet and Sports Wagering and a Proposal for Change, The[J]. Vill. sports \& Ent.lj, 2010.

[7] Cui X L. On the Inheritance, Protection and Development of National Traditional Sport "Lotus Eighteen Ring" in Yanhe County_—From the Perspective of Intangible Cultural Heritage[J]. Journal of Guizhou Normal University, 2012.

[8] Cherrett, Louise G. An Investigation Into the Character Traits of Older and Younger Siblings When Participating in Lifestyle Sports Concidering Biological and Environmental Influences[J]. 2012.

[9] Holden J T, Kaburakis A, Rodenberg R M. Occam's Razor and Sports Wagering Law[J]. Social Science Electronic Publishing, 2015. 
[10]Bowman R A, Ashman T, Lambrinos J. Undestanding Baseball Team Standings and Streaks[J]. American Journal of Operations Research, 2015, 05(5):357-366.

[11]Kelly J M. Sports Wagering Prohibition in the United States: An Exercise in Futility and the Best Development for Organized Crime[J]. Gaming Law Review \& Economics, 2011, 15(5):257-259.

[12]Pitt H, Thomas S L, Bestman A, et al. "It's just everywhere!" Children and parents discuss the marketing of sports wagering in Australia[J]. Australian and New Zealand journal of public health, 2016, 40(5):480. 